\title{
Lugar, sentido de lugar y procesos migratorios. Migración internacional desde la periferia de la Ciudad de México
}

\author{
Cristóbal Mendoza \\ Universidad Autónoma Metropolitana-Iztapalapa. Departamento de Sociología \\ Universitat Autònoma de Barcelona. Departament de Geografia \\ cmp@xanum.uam.mx
}

\author{
Diana Bartolo Ruiz \\ Consejo Nacional de Población (CONAPO) \\ Departamento de Ordenamiento Territorial \\ Dirección de Poblamiento y Desarrollo Regional Sustentable \\ dbartolo@segob.gob.mx
}

Recepción: febrero de 2011

Aceptación: junio de 2011

\section{Resumen}

A pesar de la gran atención dedicada a la reflexión teórica sobre el «lugar» y el «sentido de lugar» en la geografía, se han realizado pocos avances metodológicos, particularmente de carácter cuantitativo, para evaluar o medir el sentido de lugar. Poco frecuente, además, ha sido el uso del potencial analítico de estos conceptos geográficos para el estudio de los procesos migratorios. En este contexto, el artículo plantea el estudio del «lugar»y del «sentido de lugar» de los habitantes de Valle de Chalco-Solidaridad, municipio de la periferia de la Ciudad de México, y relaciona el sentimiento de identidad territorial con el proyecto migratorio de estas personas. Para ello, utiliza datos de una encuesta de hogares, representativa para el conjunto del municipio, complementados con 31 entrevistas semiestructuradas, realizadas a jefes de hogares seleccionados de la encuesta. Entre las conclusiones, resalta que, al margen del sentimiento de pertenencia o incluso arraigo, la migración internacional siempre será una opción, en tanto que los lugares no provean oportunidades formales de empleo ni servicios para la población.

Palabras clave: lugar; sentido de lugar; migración internacional; Ciudad de México; metodología cuantitativa.

Resum. Lloc, sentit de lloc i processos migratoris. Migració internacional des de la periferia de la Ciutat de Mèxic

Malgrat la gran atenció dedicada a la reflexió teòrica sobre el «lloc» i «el sentit de lloc» a la geografia, s'han realitzat pocs avenços metodològics, particularment de caràcter quantitatiu, per avaluar o mesurar el sentit de lloc. A més, l'ús del potencial analític d'aquests conceptes geogràfics per estudiar els processos migratoris ha estat poc freqüent. En aquest context, l'article proposa l'estudi del «lloc» i del «sentit de lloc» dels habitants de Valle de 
Chalco-Solidaridad, municipi de la periferia de la ciutat de Mèxic, i relaciona el sentiment d'identitat territorial amb el projecte migratori d'aquestes persones. Per això, utilitza dades d'una enquesta de llars, representativa per al conjunt del municipi, complementada amb 31 entrevistes semiestructurades, realitzades a caps de llars seleccionats de l'enquesta. Entre les conclusions, ressalta que, al marge del sentiment de pertinença o fins i tot d'arrelament, la migració internacional sempre serà una opció, mentre els llocs no garanteixin oportunitats formals d'ocupació ni serveis per a la població.

Paraules clau: lloc; sentit de lloc; migració internacional; Ciutat de Mèxic; metodologia quantitativa.

Résumé. Place, sens du lieu et processus migratoires: Migration internationale dès la périphérie de la ville de Mexique

Malgré la considérable attention consacrée à la réflexion théorique sur la "place» et le "sens du lieu» dans la géographie, n'existent pas trop travaux méthodologiques, particulièrement quantitatives, afin d'évaluer ou de mesurer le sens du lieu. Aussi l'usage du potentiel analytique de ces concepts géographiques pour l'étude des processus migratoires a été peu fréquent. Dans ce contexte, l'article présente l'étude du «lieu» et du "sens du lieu» des habitants de Valle de Chalco-Solidaridad, municipalité située à la périphérie de la ville de Mexique, et mets en relation l'identité territoriale avec le projet de migration de ces personnes. Pour cela, il utilise les données d'une enquête de foyers, représentant pour l'ensemble de la municipalité, additionnée de 31 entretiens semi-structurés avec chefs de foyers sélectionnés d'après l'enquête. Parmi les conclusions, l'article souligne que, hors du sentiment d'appartenance ou d'enracinement, la migration internationale sera toujours une option, tandis que les lieux ne fournissent pas d'occasions formelles d'emploi ou des services pour la population.

Mots clé: lieu; sens du lieu; migrations internationales; ville de Mexique; méthodologie quantitative.

Abstract. Place, sense of place and migration processes: International migration from the periphery of Mexico City

Geography has extensively discussed on "place» and «space». The bulk of this literature has focused on theory, with methodological accounts (particularly those quantitative) being marginal. Thus little progress has been made to assess or measure senses or place. Furthermore the analytical potential of these geographical concepts has still to be explored for migration studies. Set in this context, the article studies "place» and «sense of place» of residents in Valle de Chalco-Solidaridad, a municipality of Greater Mexico City, and explores their relevance to understand people's migration trajectories. For this, data from a representative household survey are used (plus 31 semi-structured interviews to household heads that were previously selected from the survey). Amongst conclusions, international migration comes out as a real option for people of Mexico City, regardless of their place attachment or place identity, provided the lack of formal jobs and services.

Key words: place; sense of place; international migration; Mexico City; quantitative methods. 


\section{Sumario}

Encuesta Migración, lugar y empleo en Valle de Chalco-Solidaridad

(Estado de México) (EMLE)

Migración en Valle de Chalco-Solidaridad

Vinculación funcional. Valle de ChalcoSolidaridad, un municipio con escasas oportunidades laborales
El desarraigo y la ausencia de vínculos afectivos con el territorio

Identidad y lugar

Sentido de lugar y migración internacional

Conclusiones

Referencias bibliográficas

En parte como reacción y alternativa al positivismo en geografía, ha habido, desde los años setenta, un renovado interés en los aspectos relacionados con la vinculación afectiva y la cotidianidad de las personas con los lugares. Este enfoque, conocido como humanista, valora, por encima de todo, la experiencia y declara que no existe un mundo único y objetivo, sino una pluralidad de mundos, tantos como actitudes e intenciones del ser humano (Tuan, 1974, 1977; Buttimer, 1976; Relph, 1976). Los lugares no existen como entidades, sino como representaciones que son resultado de las diferentes experiencias de las personas. Los lugares, por tanto, están llenos de significados y tienen una dimensión existencial, una vinculación emocional con el ser humano y se relacionan con un espacio concreto y unos atributos bien definidos (Buttimer y Seamon, 1980; Proshansky, Fabian y Kaminoff, 1983; Pred, 1984; Eyles, 1985; Seamon y Mugerauer, 1985; Agnew, 1987; Agnew y Duncan, 1989; Haeberle, 1988).

En los años noventa, se avanzó en la teorización sobre los vínculos emocionales de los individuos con respecto a los lugares, particularmente el sentido de pertenencia asociado a los mismos («sentido de lugar» o sense of place). En aquella década, la geografía experimentó una eclosión del número de trabajos centrados en el «lugar» (Hiss, 1990; Johnston, 1991; Altman y Low, 1992; Anderson y Gale, 1992; Rodman, 1992; Gallagher, 1993; Sack, 1993; Seamon, 1993; Massey, 1995; Basso, 1996; Twigger-Ross y Uzzell, 1996; Crang, 1998; Light y Smith, 1998). El «sentido de lugar», que se convierte en un concepto analítico clave para la geografía humanística, considera el lugar como una construcción social o una subjetivización y permite analizar la forma cómo el espacio, entendido como algo abstracto y genérico, se convierte en lugar gracias a la experiencia y a la acción de los individuos, que, viviéndolo cotidianamente, lo humanizan y lo llenan de contenidos y significados (Massey, 1995). El sentido de lugar, construido a partir de la experiencia cotidiana y de los sentimientos subjetivos de cada persona, puede llegar a concebirse con tanta intensidad que se convierte en un aspecto central en la construcción de la identidad individual (Rose, 1995). Es más, «los lugares proporcionan experiencias compartidas entre la gente y la comunidad en el tiempo» (Crang, 1998: 103), de tal forma que posibilitan la pertenencia a un colectivo en un momento determinado. 
Por el contrario, la ausencia de sentido de lugar (placelessness) se relaciona con la falta de significados de los lugares y con la pérdida de autenticidad de éstos para la persona. En este aspecto, algunos autores han destacado que la cultura del consumo y la cultura de masas han creado espacios estandarizados, atemporales y sin connotaciones emocionales, como, por ejemplo, centros comerciales, parques temáticos o nudos de comunicaciones como los aeropuertos (Relph, 1976; Arefi, 1999). Por otro lado, también se ha criticado que un exceso de énfasis en el «lugar», en un mundo que combina un doble proceso de globalización y repliegue identitario, puede favorecer la vuelta al «hogar», al «centro», a la «vivienda» e ignorar aspectos que implican la relación con el «otro», como son «horizonte», "periferia» o «viaje», lo cual puede repercutir en procesos de inclusión y exclusión e incluso xenofobia con respecto a los que no forman parte del colectivo que se identifica con un lugar (Massey, 1994; Peet, 1998; Cresswell, 2004).

En la geografía de la población, en los años noventa, con algo de retraso con respecto a la geografía humana en general, se realizó un serio esfuerzo por teorizar el espacio y el lugar en el contexto de los procesos migratorios (Mendoza, 2006a). De esta manera, la geografía de la población, particularmente la británica, abandonó un cierto empirismo de corte cuantitativo centrado en la descripción espacial de las poblaciones humanas para investigar el papel del «lugar» a la hora de entender las trayectorias migratorias y, en concreto, los significados que se otorgan a los diferentes lugares que conforman la trayectoria migratoria (Halfacree y Boyle, 1993; White y Jackson, 1995; Gutting, 1996; Findlay y Li, 1997; Silvey y Lawson, 1999; Pellegrini y Fotheringham, 2002). En esta misma línea, Pascual de Sans (2004) plantea que, durante el curso de la vida, las personas se implican con varios lugares y les dan diferentes significados, dejando, en algunos casos, «marcas» que actúan sobre diversos niveles de conciencia. Así, algunos migrantes sienten identificación geográfica o «idiotopía» con algunos lugares, como una expresión precisa de la pertenencia a un lugar (Pascual de Sans, 2004).

Añadiendo matices a la discusión teórica, a partir de la introducción del «paradigma de las nuevas movilidades» o el también llamado "giro de la movilidad" (mobility turn; Creswell, 2006; Sheller y Urry, 2006; Blunt, 2007), algunos autores han reconocido la relevancia del «lugar» para entender la complejidad de los desplazamientos migratorios contemporáneos (véase, por ejemplo, el número monográfico de la revista Journal of Ethnic and Migration Studies, coordinado por Conradson y Latham, 2005, sobre transnacionalismo urbano, o el número de la revista Environment and Planning $A$, coordinado por Sheller y Urri, 2006, que revisa diferentes experiencias de movilidad a partir del análisis de lugares concretos). Resaltan, en este contexto, también algunos estudios empíricos que yuxtaponen los niveles transnacional y local, en los que se defiende que la cotidianidad de algunos colectivos de inmigrantes es, en sí misma, transnacional, pero se recrea y se construye en lugares diferentes (por ejemplo, Campbell, 1996; Ehrkamp, 2005; Mendoza, 2006b). En esta línea, Mitchell (2004) apunta que el obje- 
tivo de la geografía a la hora de abordar el estudio de la migración internacional debería consistir en el análisis de los movimientos y las prácticas de los migrantes materializadas en lugares y contextos concretos, así como en el estudio de los flujos migratorios con relación a las construcciones culturales sobre nación, ciudadanía y sociedad.

A pesar de los evidentes avances teóricos, desde nuestro punto de vista, se han realizado pocos avances metodológicos a la hora de buscar indicadores que sirvan para evaluar o medir la relevancia del «sentido de lugar», particularmente en el caso de los colectivos migrantes. De hecho, el rechazo a visiones positivistas, y el énfasis en las subjetividades, hace difícil extraer conclusiones generales sobre experiencias que, per se, son personales o intentar metodologías de corte cuantitativo. Creemos, en este sentido, de interés los acercamientos metodológicos procedentes de otras disciplinas que han retomado el concepto a la luz de lo que algunos autores han denominado "giro espacial» de las ciencias sociales (Crang y Thrift, 2000; Thrift, 2004). Así, este concepto que principalmente había sido abordado desde enfoques fenomenológicos, está siendo examinado e incorporado desde posturas más positivistas, desde la psicología medioambiental (Hidalgo y Hernández, 2001; Hernández et al., 2007), las ciencias ambientales (Williams y Stewart, 1998; Raymond et al., 2010) o incluso la administración de recursos naturales (Jorgensen y Stedman, 2006; Halpenny, 2010).

En efecto, el concepto permite realizar un abordaje integral y dinámico de las relaciones que establecen o desarrollan las personas con sus lugares en un sentido amplio. Dicho con otras palabras, es útil para estudiar las relaciones hacia los lugares, ya sea entendido como recursos naturales, paisajes, ecosistemas, símbolos, fuente de identidad o sitios recreacionales (Williams y Stewart, 1998; Eisenhauer et al., 2000). De esta manera, todas las definiciones de sentido de lugar involucran o incluyen un punto en el que los elementos físicos, las actividades y los significados atribuidos al lugar se entrelazan con la experiencia del lugar de las personas o los grupos que los ocupan. Además, este concepto también remite a la consideración y al conocimiento del contexto cultural, histórico y espacial que revisten ciertos lugares o ubicaciones en los cuales una multiplicidad de significados, valores e interacciones sociales se recrean o tienen lugar (Williams y Stewart, 1998). Incluso se podría afirmar, aunque no se haya visto en general así en la literatura, que el sentido de lugar se podría erigir como un concepto puente entre la geografía y otras disciplinas y un punto de enlace entre las geografías humanistas y otras de carácter más positivista.

En este sentido, se han desarrollado varios estudios que abordan la construcción del lugar y el sentido de lugar desde la psicología medioambiental y social que están basados en aproximaciones positivistas, principalmente desde enfoques conductivistas (behavioural approaches) (Shamai, 1991; Lalli, 1992), que emplean diferentes métodos para inferir y medir la intensidad del sentido de lugar y las variables o los predictores que lo configurarían. En esta misma línea, Jorgensen y Stedman $(2001,2006)$ definen tres dimensiones analíticas del sen- 
tido de lugar: i) apego al lugar, ii) identidad asociada al lugar, y iii) vinculación funcional al lugar, donde cada una de éstas se refieren a una forma particular de relacionarse con el espacio.

Para Shamai (2005), por ejemplo, la escala para medir el sentido de lugar se clasifica según cuatro atributos: polaridad, métodos directos o indirectos, dimensiones y componentes. El atributo de polaridad identifica los valores extremos (polos) de las actitudes positivas y negativas hacia los lugares. El método directo o indirecto se refiere al hecho de conocer si el lugar existe en el bagaje del entrevistado o si se deriva la existencia del sentido de lugar a través de comentarios indirectos. Con el método de componentes, la escala mide la intensidad del sentido de lugar, que se conforma por una o varias preguntas (o componentes). De manera similar, el método de dimensiones consiste en agrupar varias preguntas o componentes en distintas escalas que luego se concentran en una escala compuesta.

Retomando esta discusión, este artículo se centra, a partir de los datos de una encuesta, complementados con información cualitativa, en el estudio del sentido de lugar, distinguiendo el vínculo funcional del afectivo, de los habitantes del municipio de Valle de Chalco-Solidaridad; municipio con altos índices migratorios situado en la periferia de la Zona Metropolitana de la Ciudad de México (véase mapa 1). Partimos de la hipótesis de que la forma cómo los lugares son construidos y representados por los migrantes puede desempeñar un papel crucial en las decisiones de migrar o permanecer, así como en el establecimiento de redes sociales locales o transnacionales.

El artículo, primero, expone brevemente la metodología del estudio, para, posteriormente, centrarse en los flujos migratorios en Valle de Chalco-Solidaridad, en el contexto de cambio de patrón de las migraciones de México a Estados Unidos. A continuación, se centra en el análisis del vínculo funcional de los residentes en Valle de Chalco-Solidaridad, entendido como el nivel de dependencia que desarrollan los residentes de un área o locación en cuanto dicho lugar procura o/y satisface sus objetivos y necesidades personales en comparación con otros lugares (Hidalgo y Hernández, 2001; Jorgensen y Stedman, 2006; Hernández et al., 2007). Posteriormente, se analiza el vínculo afectivo («apego» al lugar) que desarrollan las personas o los grupos hacia algunos lugares o emplazamientos físicos, cuya característica principal es la tendencia a mantener relaciones cercanas (Hidalgo y Hernández, 2001; Hernández et al., 2007; Raymond et al., 2010) de los residentes de Valle de Chalco-Solidaridad. Este apego al municipio puede comportar identidad territorial («arraigo»), de tal forma que las personas se describen a sí mismas en términos de su pertenencia a un lugar específico. Para el estudio de estas dimensiones analíticas, utilizaremos datos proporcionados por la encuesta Migración lugar y empleo en Valle de Chalco-Solidaridad (EMLE a partir de ahora), realizada en dicho municipio, y entrevistas realizadas a hogares seleccionados a partir de la encuesta (metodología que se presenta en el próximo apartado). 


\section{Encuesta Migración, lugar y empleo en Valle de Chalco-Solidaridad (Estado de México) (EMLE)}

La EMLE es una encuesta de hogares representativa para la totalidad del municipio de Valle de Chalco-Solidaridad (véase mapa 1), que fue realizada por la Universidad Autónoma Metropolitana-Iztapalapa. El tamaño de muestra, que fue de 759 hogares, se fijó a partir de un intervalo de confianza de $95 \%(2 \sigma)$, bajo el supuesto de máxima incertidumbre $(P=Q=50)$ y contempla un error del 3,6\%. La técnica de muestreo fue probabilística y los hogares se escogieron de forma aleatoria a partir de la cartografía detallada de Instituto Nacional de Estadística y Geografía, INEGI (2007) para este municipio, por AGEB (unidades geoestadísticas básicas) y manzana, que constituyó el marco muestral. El trabajo de campo se realizó durante los meses de abril y mayo de 2007, la validación de la información, en junio y julio, y la codificación de la encuesta se llevó a cabo durante los meses de septiembre-diciembre de ese año. Los objetivos de la encuesta se centraron en, por un lado, estudiar las trayectorias migratorias y laborales de los resi-

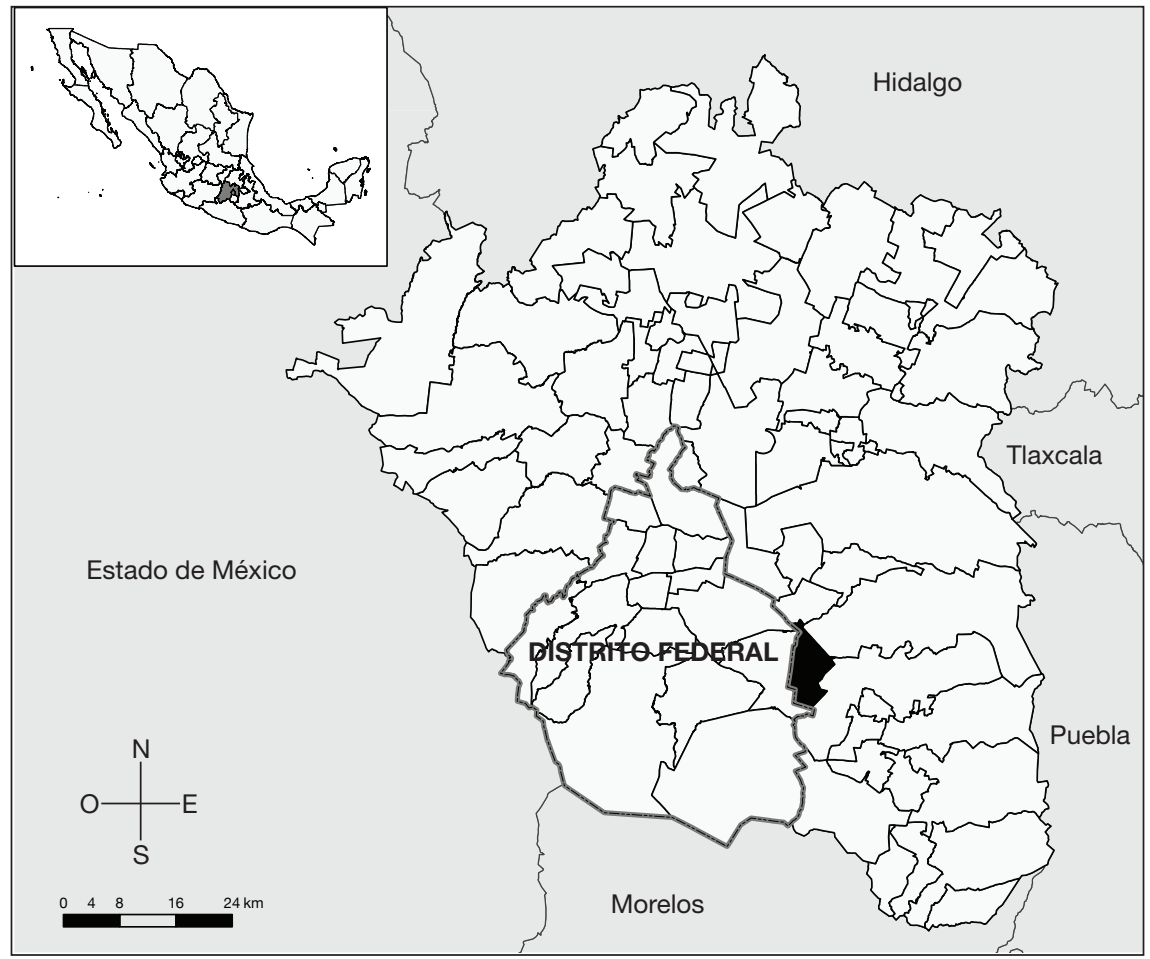

Mapa 1. Ubicación de Valle de Chalco-Solidaridad (en negro), Estado de México, en el contexto de la Zona Metropolitana de la Ciudad de México. Autora: Diana Bartolo Ruiz. 
dentes en este municipio y, por otro, explorar la relevancia del lugar para entender los procesos migratorios y las trayectorias laborales de los habitantes de este municipio del Estado de México. En ese segundo aspecto, se centra este artículo.

El cuestionario consta de cuatro grandes bloques. El primero consiste en un cuadro donde se recogía la información sociodemográfica básica de todos los miembros del hogar (sexo, estado civil, nivel de educación y relación con la persona que responde al cuestionario). A partir de los 759 hogares encuestados, se recabó información sociodemográfica de 3.488 individuos. La parte segunda del cuestionario se centra específicamente en la migración internacional a los Estados Unidos. Concretamente, se inquiría información sobre el primer y el último viajes a los Estados Unidos, el trabajo en ese país, el estatus legal en los EUA e información, si es el caso, sobre el retorno a México de todos los miembros del hogar. El apartado 3 del cuestionario recaba información de las trayectorias laborales y migratorias de los jefes de hogar, mientras que el bloque 4 se centra en las cuestiones geográficas. En concreto, se preguntaba a los encuestados sobre los diferentes lugares donde realizaban las actividades cotidianas (trabajo, ocio, escuela), así como opiniones e impresiones sobre los lugares que eventualmente conforman (o pueden conforman) su trayectoria migratoria (lugar de origen, Valle de Chalco-Solidaridad y Estados Unidos). Así, se pedía escoger entre diferentes enunciados, ordenados de acuerdo con su carga afectiva, y dar tres adjetivos (o palabras o frases) que definieran la opinión del encuestado con respecto al lugar de origen, el municipio de residencia y los Estados Unidos. Estos adjetivos se agruparon, posteriormente, en el proceso de codificación de acuerdo con la intensidad y el signo de la respuesta.

Para complementar la información de la encuesta, se realizaron entrevistas semiestructuradas a 31 jefes de familia de hogares que previamente habían sido encuestados. La selección se realizó a partir de varios indicadores, como la estructura del hogar, la edad y el sexo del encuestado, así como los patrones de migración, movilidad y circularidad de los miembros de la familia.

\section{Migración en Valle de Chalco-Solidaridad}

El municipio de Valle de Chalco-Solidaridad se ubica al este del área metropolitana de la Ciudad de México (véase mapa 1) y es un territorio urbano que experimentó un gran crecimiento demográfico en los años noventa (una tasa de 5,3\% para el período 1990-95; tabla 1). A partir de 1995, sin embargo, el ritmo de crecimiento ha disminuido sustancialmente y ha llegado a ser casi inapreciable en el quinquenio 2000-2005.

El crecimiento del municipio se ha debido, en parte, a la expansión (caótica) de la Ciudad de México y su zona metropolitana. Hiernaux (1995), en este sentido, explica que las políticas urbanas del Distrito Federal, particularmente la apertura del mercado inmobiliario, la falta de política pública de vivienda y el aumento de las tarifas de los servicios e impuestos, propiciaron 
Tabla 1. Evolución de la población en el municipio de Valle de Chalco-Solidaridad (Estado de México)

\begin{tabular}{lccc}
\hline Año & Población & Crecimiento & Tasa de crecimiento (\%) \\
\hline 1990 & 219.773 & - & - \\
1995 & 287.073 & 67.300 & 5,3 \\
2000 & 323.461 & 36.388 & 2,4 \\
2005 & 332.279 & 8.818 & 0,5 \\
\hline
\end{tabular}

Fuentes: dato de 1990: Lindón (1999); datos de 1995, 2000 y 2005: Instituto Nacional de Estadística, Geografía e Informática, INEGI (2010a, 2010b, 2010c). Tasas de crecimiento: elaboración propia.

la expulsión de población de las áreas centrales de la ciudad y de las zonas «próximas» de la periferia, como Iztapalapa, a áreas más alejadas del área metropolitana. Como afirma Olivera (2004), los pobres de las ciudades han sido empujados progresivamente hacia la periferia, ya que encontraron viviendas más baratas en el marco de fraccionamientos ilegales sobre terrenos de propiedad ejidal ${ }^{1}$. Aunque es ilegal, este método de desarrollo urbano se institucionalizó (Azuela, 1989; Iracheta, 2003) hasta el punto de que, para los pobres, la ilegalidad constituye la forma más «racional» de apropiación del espacio urbano (Hiernaux y Lindón, 1997).

De esta manera, Valle de Chalco-Solidaridad se convirtió en receptor neto de población, ya fuera del Distrito Federal o de otros estados. Aunado a estos desplazamientos internos, este municipio, al igual que la mayoría de la periferia de la zona metropolitana de la Ciudad de México que hasta hace dos décadas no participaba en la migración internacional (o lo hacía de manera marginal), se ha incorporado al flujo migratorio a los Estados Unidos (EUA), lo que contribuye a modificar y a hacer más complejas las dinámicas y modalidades migratorias hacia el país del norte (Canales, 2002).

En lo referente a la migración internacional, según datos del Consejo Nacional de Población (2002), el municipio cuenta con un grado de intensidad migratorio bajo en el año 2000, patrón que se repite en el resto de municipios del Estado de México que conforman el área metropolitana de la ciudad. De los 71.543 hogares del municipio, CONAPO estimaba que el 3,7 por ciento contaba con migrantes en Estados Unidos; el 2,5 por ciento recibía remesas; un 0,5 tenía migrantes circulares, y un escaso 0,2 por ciento, migrantes de retorno (Consejo Nacional de Población, 2002). Por el contrario, los datos de nuestra

1. El ejido es un sistema de tenencia que se creó como resultado de la revolución mexicana a mediados de la década de 1920 para garantizar el acceso a la propiedad de la tierra a la población rural. El sistema de tenencia del ejido incluía tierra parcelada, tierra de uso común y solares urbanos. El derecho de usufructo sobre las parcelas individuales permitía a los ejidatarios cultivar la tierra, pero restringía su venta, alquiler o uso como garantía para un crédito. En 1992, se aprobó una modificación de la Constitución mexicana que posibilita la venta de parcelas (Galeana Rodríguez, 2005). 
encuesta apuntan a una mayor incidencia de la migración a Estados Unidos y del retorno en los hogares.

Concretamente, de 759 hogares encuestados, nuestros datos arrojan que 146 contaban con algún miembro que emigró o había emigrado a Estados Unidos, lo cual constituye el 19,2\% del total de hogares. Esta cifra se reduce al $8 \%$ si sólo se toma en cuenta aquellos hogares con miembros que todavía residen en Estados Unidos. Por otra parte, si, en vez de los hogares, consideramos a los miembros de los hogares encuestados, el número de migrantes asciende a 203, que constituye un 5,8 por ciento del total, aunque este porcentaje disminuye a un 3,2 por ciento si sólo tomamos en cuenta a los que todavía están en Estados Unidos. El índice de retorno, calculado respecto a las 203 personas con experiencia migratoria internacional, fue de alrededor de un 40 por ciento (un total de 89 habían regresado). Por último, la media de migrantes por hogar migrante es de 1,4. Además, la mayoría de las personas (un 70,3\%) ha realizado un único viaje, principalmente en el periodo 2000-2007. De hecho, más de la mitad del total de las 203 personas con experiencia migratoria internacional realizaron su primer viaje en ese periodo (véase la tabla 2).

$\mathrm{Al}$ hacer una lectura de conjunto, podemos deducir que Valle de ChalcoSolidaridad es un municipio que se ha integrado recientemente, pero con fuerza, a la migración internacional, lo cual se ve reflejado en una alta intensidad migratoria, medida a partir del número de hogares con migrantes, poca circularidad y un retorno de un 40 por ciento, datos que se podrían entender en el contexto de consolidación de los flujos migratorios internacionales en el municipio. En el próximo apartado, nos centraremos en la expansión de la migración internacional y la relacionaremos con la falta de oportunidades laborales del municipio.

Tabla 2. Año de realización del primer viaje a Estados Unidos

\begin{tabular}{|c|c|c|c|c|c|c|}
\hline & \multicolumn{2}{|c|}{ Migrantes de retorno } & \multicolumn{2}{|c|}{ Inmigrantes en EUA } & \multicolumn{2}{|c|}{ Total } \\
\hline & Núm. & $\%$ & Núm. & $\%$ & Núm. & $\%$ \\
\hline Antes de 1980 & 5 & 5,6 & 1 & 0,9 & 6 & 2,9 \\
\hline $1980-1989$ & 13 & 14,6 & 7 & 6,1 & 20 & 9,9 \\
\hline $1990-1994$ & 11 & 12,4 & 9 & 7,9 & 20 & 9,9 \\
\hline $1995-1999$ & 16 & 18,0 & 17 & 14,9 & 33 & 16,3 \\
\hline $2000-2007$ & 42 & 47,2 & 76 & 66,7 & 118 & 58,1 \\
\hline $\mathrm{NS} / \mathrm{NC}^{*}$ & 2 & 2,2 & 4 & 3,5 & 6 & 2,9 \\
\hline Total & 89 & 100,0 & 114 & 100,0 & 203 & 100,0 \\
\hline
\end{tabular}

* No sabe o no contesta.

Fuente: encuesta Migración, lugar y empleo en Valle de Chalco-Solidaridad, abril-mayo de 2007. 


\section{Vinculación funcional. Valle de Chalco-Solidaridad, un municipio con escasas oportunidades laborales}

La vinculación funcional concierne a la capacidad y a las características de una región o de un lugar particular para satisfacer los objetivos y las necesidades personales, siempre en comparación con otros lugares o espacios potenciales. En este sentido, los indicadores sobre migración, y el hecho de que la mayoría de las migraciones internacionales desde el municipio sean laborales es ya un indicador en sí mismo de la falta de oportunidades laborales en Valle de Chalco-Solidaridad. A título de ejemplo, Margarita ${ }^{2}$ menciona la facilidad de empleo y las mejores condiciones laborales en Estados Unidos:

[...] Si la facilidad de empleo que hay allá [Estados Unidos] hubiera aquí, la verdad no hubiera tanta migración. Eso es lo que hace que se vayan para allá, porque aquí les cuesta mucho trabajo conseguir empleo. Ésa es una de las situaciones por la cual mis hijos están allá [...] Mi hijo Omar que tiene ocho años allá. Él aquí trabajaba en la policía y la verdad se fregaba mucho [y la verdad lo pasaba muy mal], pero ganaba muy poco y la verdad, no es por nada, pero allá tiene una calidad de vida mucho mejor. Le da a sus hijas una calidad de vida mucho mejor. Él extraña mucho el venirse para acá por su familia, pero también lo piensa mucho. Por sus hijas, no le gustaría que estuvieran aquí. (Margarita, Distrito Federal, 58 años, ama de casa)

En esta misma línea, se expresa Noé, que forma parte del 30\% de personas que han realizado más de un migración a los Estados Unidos. En concreto, ha migrado siete veces: las dos primeras al área de Los Ángeles, y el resto, a Ohio. En la entrevista, Noé comenta que, debido a que el trabajo de compraventa de ropa que tenía en su garaje en México no funcionaba bien, tenía contemplado regresar a Estados Unidos, en esta ocasión a Atlanta, donde tiene algunos conocidos. En sus propias palabras:

Yo aquí no la veo, yo había puesto, [...] quería poner un negocito de ropa. Lo puse, pero no pega, mire y aayy y ahorita salgo el día 9 de abril [para Atlanta]. [El negocio] saca, lo que se vendió en el día, es para el día de la casa y ya, es todo. Gastos, gastos de todos, y ahorita mi esposa trabaja en la costura, y vendemos aquí, en el tianguis [mercadillo], y este, y yo me doy cuenta de los gastos que hay.

¿Realmente le gusta Estados Unidos?

Sí, mucho.

¿Qué es lo que le gusta de vivir ahi, la forma de vivir, que hay trabajo?

Que tengo para todo, no tengo preocupaciones de dinero [...] que el dinero es muy necesario para todo, para todo, digo, mi familia aquí está feliz, viven bien, porque tienen. Yo les estoy mandando y yo estoy bien allá, porque ando bien, ando cómodo. Aquí no puedo comprar un carro y allá lo tengo en un ratito.

(Noé, Buena Vista, Michoacán, 44 años, trabajador autónomo)

2. Todos los nombres usados en este artículo son pseudónimos. 
Este entrevistado apunta que México no garantiza «vivir bien», y la posibilidad de emigrar es una oportunidad en situaciones de crisis, en un contexto de alta precariedad laboral y penuria económica familiar. En este sentido, quizá cabría recordar los datos sobre pobreza del área metropolitana de la Ciudad de México. Según datos de Boltvinik (citado en Parnreiter, 2002), casi 11 millones de personas (un 61\% de la población de la zona metropolitana) vivían en condiciones de pobreza en el año 2000, lo cual representaba un incremento absoluto de 3,5 millones con respecto a 1984. Además, el número de pobres extremos, según esta misma fuente, ascendía a más de siete millones de personas en ese año, mientras que en 1984 era de 2,7 millones (Parnreiter, 2002).

Las condiciones de pobreza del municipio están relacionadas directamente con la precariedad del mercado laboral. En este sentido, Hiernaux (1999) calculó que un tercio de los empleos en los barrios periféricos del este de la Ciudad de México, donde se encuentra Valle de Chalco-Solidaridad, son asalariados, de baja remuneración, inestables y poco calificados. Sin salario, sin trabajo fijo, en ausencia de seguridad social y prestaciones por desempleo, la población pobre de las periferias se encuentra cada vez más aislada (Hiernaux, 1999). En el caso concreto de Valle de Chalco-Solidaridad, Escobar et al. (2006) apuntan, además, que en este municipio no existe industria ni servicios, de modo que la mayoría de los residentes tienen que desplazarse al Distrito Federal o a otros puntos del área metropolitana para trabajar, y que la duración del viaje oscila entre una y dos horas. La falta de empleo plantea que muchos jóvenes de este municipio vean en la migración internacional una oportunidad de futuro, a pesar de las dificultades para cruzar la frontera de forma ilegal (Escobar et al., 2006).

Las condiciones de precariedad laboral y de pobreza del municipio pueden estar relacionadas con el bajo nivel educativo de los habitantes de Valle de Chalco-Solidaridad. Nuestra encuesta es clara en este sentido. Sólo un 11,2\% de los encuestados tiene estudios universitarios, mientras que las personas que no han acabado la educación primaria suman un 19,1\%. Estos datos son similares a los promedios observados para el conjunto de México (un 11,4\% y un $19,9 \%$ en 2010, respectivamente), pero sustancialmente diferentes a los del Distrito Federal. Así, el 19,5\% de la población de 18 años y más cuenta con estudios superiores en el DF, mientras que aquellos que no acaban la educación primaria en la entidad constituyen un $8,7 \%$, de acuerdo con los datos del Censo de Población y Vivienda del año 2010.

En este contexto, quizá sea difícil establecer vínculos funcionales o afectivos con un territorio que no parece proveer de forma satisfactoria las necesidades más básicas de la población. El municipio, por otro lado, tampoco satisface los servicios de recreación y se presenta como un lugar inseguro y problemático. De ahí que un $43 \%$ de los encuestados declaró que «si pudiera, viviría en otro lugar». Además de las diferencias en cuanto a salarios y a la calidad de los servicios y de la infraestructura urbana, que, de acuerdo con los entrevistados, son siempre mejores en el Distrito Federal, es recurrente que los entrevistados afirmen que no «están a gusto» en el municipio por la inseguridad. El muni- 
cipio se vive como un lugar complicado y hostil para sus residentes, tal como muestra el siguiente fragmento de entrevista de una persona que residió en el DF y tiene tres hijos en los Estados Unidos:

[...] Pues no me gusta muy bien aquí porque uno no puede salir fácilmente, porque uno ya viene y si le falta algo entra alguien a robar, porque aquí hay muchos malvivientes.

¿Usted se siente segura aqui en Valle de Chalco?

No, por eso cuando yo llego a salir se queda mi esposo y si es él, me quedo yo, y la casa nunca se queda sola.

(Cirila, Amanalco, Estado de México, 60 años, vendedora de frutas)

De esta manera, en lo concerniente a la vinculación funcional hacia este territorio, lo que emerge de las entrevistas es que el municipio es visto como un proveedor deficiente de la mayoría de los servicios, oportunidades de trabajo y esparcimiento, y sólo ofrece oportunidades limitadas para las actividades cotidianas y laborales, además de ser un lugar que implica muchos riesgos de seguridad. Estas deficiencias, sin embargo, no tienen por qué ser indicativas forzosamente de una falta de implicación afectiva de los habitantes con el territorio.

\section{El desarraigo y la ausencia de vínculos afectivos con el territorio}

Como se ha visto en los extractos de las entrevistas anteriores, la precariedad laboral de muchos residentes en Valle de Chalco-Solidaridad sitúa a estas personas en riesgo de exclusión social, de forma que la migración internacional es una opción para muchos hogares. De hecho, el crecimiento del municipio se ha debido al «arrinconamiento» de la población con menos recursos de la Ciudad de México hacia su periferia; población que no había podido acceder a otro segmento del mercado habitacional y consigue construir una casa, en muchos casos, de forma irregular.

El hecho de construir una casa, sin embargo, no implica forzosamente que se desarrolle un sentido de pertenencia con relación a Valle de ChalcoSolidaridad. De hecho, se observa una clara disyuntiva en las entrevistas entre los discursos sobre la "casa» y los referentes a "Valle de Chalco-Solidaridad». La primera es el hogar que se ha construido con mucho esfuerzo y que, en algunos casos, depende de las remesas para su finalización y el segundo es un lugar hostil, en el que no participan y del que no se sienten parte, que no constituye una comunidad para los encuestados.

Como pone de manifiesto la EMLE, la mayoría de los encuestados $(44,9 \%)$ están a gusto en su casa, aunque un tercio afirma que se cambiaría de casa, si pudiera. Este último porcentaje es mucho más bajo que el de encuestados que afirma que abandonaría Valle de Chalco, en caso de que fuera posible, que asciende al 43,0\% (tabla 3). Estos datos, en cierta manera, son previsibles, dado que la llegada a Valle de Chalco-Solidaridad coincide, en muchos casos, con el acceso a la propiedad de la casa. 
Tabla 3. Identificación de los encuestados con la casa y el municipio

\begin{tabular}{|c|c|c|}
\hline & $N$ & $\%$ \\
\hline \multicolumn{3}{|l|}{ Casa } \\
\hline Me gustaría vivir siempre en esta casa & 163 & 21,7 \\
\hline Me gusta la casa donde vivo & 338 & 44,9 \\
\hline Si pudiera, me cambiaría de casa & 251 & 33,4 \\
\hline \multirow[t]{2}{*}{$N$} & 752 & 100,0 \\
\hline & $N$ & $\%$ \\
\hline \multicolumn{3}{|l|}{ Valle de Chalco-Solidaridad } \\
\hline Me gustaría vivir siempre en Valle de Chalco & 191 & 25,5 \\
\hline Me gusta Valle de Chalco & 238 & 31,5 \\
\hline Si pudiera, viviría en otro lugar & 323 & 43,0 \\
\hline$N$ & 752 & 100,0 \\
\hline
\end{tabular}

Fuente: encuesta Migración, lugar y empleo en Valle de Chalco-Solidaridad, abril-mayo de 2007.

Es más, a partir de un análisis de correlación de Spearman entre las opiniones sobre el municipio y la casa, encontramos una correlación media-alta y positiva $(0,6)$, con un nivel máximo de significación estadística $(<0,001)$; coeficientes que apuntan a que una parte importante del arraigo a Valle de Chalco se sustenta en la dimensión física de la vivienda. El vínculo con la casa $y$, por ende, con el municipio se debe entender en el contexto de la propia historia del lugar, en la «lucha» de los primeros pobladores por conseguir los servicios y la infraestructura básica, tal como describe esta entrevistada que ha residido en Valle de Chalco-Solidaridad durante veinticuatro años:

Sí, desde siempre hemos vivido aquí, por eso ahora tenemos la opción de comprar por parte del seguro (crédito hipotecario de un organismo público) casas de esas... No, porque tantos años que ha sufrido uno aquí como para comprar una casa e irse y volver a empezar ¿no?

$Y$ además a ustedes les costó todo ¿no? O sea luchar para que les pusieran agua, luz. ¿Cómo fue eso, a ver cuéntanos?

Pues eso... De hecho, íbamos cada martes al centro, al Distrito a pedir la luz, el agua..., pero no nos la daban; nos la dieron hasta que entró Salinas [presidente de México de diciembre de 1988 a noviembre de 1994, del Partido Revolucionario Institucional]. (Elizabeth, Nezahualcóyotl, Estado de México, 38 años, pintora)

De esta forma, la lucha ligada al acceso a la propiedad y a la dotación de servicios provoca una identificación de los actores con el espacio ocupado, lo cual da realidad a un territorio sentido como propio, vivido cotidianamente y que les permite identificarse como residentes del municipio. Además, como 
ha sido observado en el caso de otros colectivos de migrantes, la construcción y la mejora de las viviendas ha sido financiada con las remesas de los Estados Unidos, tal como ilustra la siguiente cita:

[...] Cuando él [el padre] se fue [a Estados Unidos] teníamos dos cuartos. La cocina junto con la salita eran en un mismo cuarto y la habitación era para todos. Ahorita cada quien tiene su recámara, ya hay sala y la cocina aparte. (Ana Jessica, Valle de Chalco, Estado de México, 20 años, estudiante y empleada en el negocio familiar)

En este sentido, la construcción de la casa representa un logro familiar y personal que se ha conseguido con mucho esfuerzo y en el que prácticamente todos los miembros se han visto implicados. Como menciona Lindón (2005a: 158), «la construcción de un vínculo más fuerte con la casa deriva de que ésta reposiciona al sujeto como poseedor de algo valorado socialmente, que otorga existencia y visibilidad social a las personas». Esta condición de poseedor le da al habitante de la periferia la entrada al mundo de los propietarios (aunque, en muchos casos, la propiedad no se encuentre regularizada), ya que, por un lado, muestra que acepta el código social que dicta la importancia de tener algo propio y, por otro, siente que la sociedad lo incluye a partir de ese acceso y adquiere visibilidad social. A pesar de que esta forma de darle sentido a la casa trae consigo cierto anclaje del sujeto al territorio, el vínculo sigue siendo utilitario, pues es un lugar que da identidad por posesión.

Es más, un tercio de los entrevistados (el 33,4\%) preferiría cambiar de casa, lo que parece indicar un gran desapego con respecto a la actual vivienda y, por ende, con el municipio de residencia. A este respecto, Lindón (2005a), a partir de varios estudios realizados en este municipio, encontró que la adquisición o la construcción de una casa implicaba un cierto vínculo entre el sujeto y el espacio de vida, pero que no siempre se consolida un vínculo profundo como el arraigo o apego al lugar. A esta forma de habitar, esta autora la ha definido como «habitar del rechazo atópico». El espacio de vida se vacía de significados y la relación que se establece con el lugar habitado es utilitaria, ya que, aunque la mayor parte del tiempo se permanezca en el mismo lugar, no se trata de una localización valorizada, sino más bien rechazada y desacreditada (Lindón, 2005b).

\section{Identidad y lugar}

Es difícil que un lugar valorado negativamente por sus residentes, donde la casa o el acceso a la propiedad es su aspecto más positivo (o el único aspecto positivo), con escasas posibilidades laborales y de ocio, y con elevadas tasas de migración internacional, pueda incidir en un sentimiento de identidad. Uno de los aspectos que remite a la identidad territorial está relacionado con los rasgos existentes en el entorno social y físico y la manera como éstos son asumidos 
como propios y, por tanto, pueden ser capaces de generar una identidad particular (Ortiz Guitart, 2004; López, 2005). En nuestras entrevistas, se preguntó qué es lo que se consideraba como característico de Valle de Chalco, qué lo distinguía de otros municipios. Los entrevistados, en general, tuvieron dificultad para identificar estos rasgos característicos. Las referencias fueron, más bien, relativas a la rápida urbanización del municipio, a las mejoras materiales como la pavimentación o a la desaparición de los campos de cultivo, pero con pocas referencias a lugares concretos. Un ejemplo de esta opinión es resumido por Cirila, una comerciante informal del municipio:

\section{Si le preguntaran que es lo característico de Valle de Chalco, ¿qué respondería? Pues, Valle de Chalco es..., pues así como estaba ya no está. Ya ha cambiado bastante, ya están las calles pavimentadas. La avenida ya la arreglaron con sus lámparas y todo eso y estas dos calles, porque así por calles van pavimentando. (Cirila, Amanalco, Estado de México, 60 años, vendedora de frutas)}

Aguilar (2000), a partir de una investigación realizada en este mismo municipio, coincide en que, por su propia dinámica urbana, el lugar se define a partir de lo que no es, de lo que carece. Es decir, lo característico del municipio está dado por la ausencia, lo cual, a veces, se contrasta con las condiciones de vida pasadas o con las expectativas de futuro, en muchos casos, en los Estados Unidos. En otras palabras, la distintividad viene dada en función de los servicios y del equipamiento de otros espacios urbanos contiguos, o incluso foráneos.

Por otro lado, además del reconocimiento de que hay un déficit de servicios y de infraestructura urbana, está también presente, en las entrevistas, la noción y la certeza de que Valle de Chalco-Solidaridad mejora, que está más conectado y que en el futuro habrá más servicios. No obstante, esta percepción de que Valle de Chalco-Solidaridad ha cambiado y de su rápido crecimiento y urbanización, de cierta mejora de los servicios básicos y de las infraestructuras, la rápida expansión del municipio también se asocia con un aumento en la delincuencia y la pérdida de muchas prácticas comunitarias, como la relación con los vecinos o un cierto ambiente de camaradería en la adversidad. Por ejemplo, Rafael nos comenta que Valle de Chalco-Solidaridad ha cambiado, que se ha vuelto más inseguro, y ello «es por la gente que ha llegado, ahora muchos lugares se rentan y quién sabe qué costumbres o mañas traiga esa gente» (Rafael, Huajuapan de León, Oaxaca, 41 años, comerciante), También Elizabeth, una de las primeras pobladoras de lo que hoy es la colonia Providencia relata el aumento en la inseguridad:

[antes] no había gente, hasta tendías afuera, nosotros aquí no teníamos ni puerta... Ni nada, o sea nada, era un cuartito de lámina, y no había rateros y ahora que [la casa está construida]..., por eso bardeamos [pusimos una barda o valla], hay bastantes rateros

Si, es lo que me comentan, la inseguridad ¿no?

Pero fíjate que no es gente de aquí. 


\begin{abstract}
¿No?
No, porque a mí, inclusive, me han asaltado aquí en la mera esquina... Y no es gente de aquí, tengo añísimos viviendo aquí y conoces a la mayoría de la gente aunque sea de vista, y no es gente de aquí.

(Elizabeth, Nezahualcóyotl, Estado de México, 28 años, pintora)
\end{abstract}

En este sentido, es importante mencionar que, en la identidad del lugar, no se trata sólo de reconocer las características particulares de un entorno, sino también cómo éstas pueden llegar a formar parte de los procesos de adscripción y diferenciación, respecto de categorías sociales que señalan rasgos de pertenencia, por ejemplo entre los habitantes de Valle de Chalco-Solidaridad, los de aquí o los recién llegados. El crecimiento del municipio y la llegada de más personas parecen haber diluido antiguas prácticas vecinales y comunitarias. También es importante mencionar que tanto Lindón (2000) como Aguilar (2000), encontraron que rige el principio de que «la distancia social protege», de ahí que en Valle de Chalco se observa un tipo de sociabilidad muy restringida.

No me gusta Valle de Chalco, nunca me ha gustado, pero no porque esté feo, o esté ahora bonito, muy urbanizado. Porque no me siento muy arraigado aquí, con ese calorcito donde llegas a un lugar que conoces, quizá porque conozco muy poca gente. Muy poca gente me conoce. $\mathrm{O}$ porque en realidad es un lugar grandísimo. Me siento en un lugar muy frío, no físicamente, muy frío del calor de la gente. Conozco gente muy buena onda. Mucha familia mía vive aquí, mi mamá, muchos tíos, mi familia más cercana, mi sobrina. Ese ha sido mi problema. Nunca me he adaptado a Valle de Chalco. Me he bloqueado. No me gusta tal vez porque he vivido mucho tiempo en Los Reyes, La Paz. Tal vez porque, entre mis proyectos, esté vivir en Los Reyes. ¿Por qué compramos aquí, y no en Los Reyes? Una porque salió la oportunidad de comprar aquí el terreno y fincar, y otra a mi esposa le gusta aquí, en esta zona. Mis hijos van a la escuela aquí, en Valle de Chalco. Fue más cómodo y más barato invertir el dinero aquí, en este terreno y en esta zona.

(Juan, Los Reyes, Estado de México, 36 años, taxista)

Como pone de manifiesto Juan, las relaciones sociales en el municipio son vistas como complicadas por la mayoría de los entrevistados, que prefieren el trato con la familia. Las largas jornadas laborales y la conflictividad del barrio no ayudan a vincularse a una supuesta comunidad. Por ejemplo, Rocío, de 24 años, que residió de niña en el DF y que se trasladó con la familia, al comprar una vivienda, a Valle de Chalco-Solidaridad, se expresa en términos similares:

\title{
¿Se llevan bien con los vecinos de la colonia?
}

Nada más nos saludamos de buenos días, buenas tardes y ya [...]. No te deja nada bueno el ser amable. Sí, es bueno ser amable, pero no te deja nada bueno. A final de cuentas, sales embarrado en cualquier cosa, entonces mejor buenos días, buenas tardes y hasta ahí.

(Rocío, Distrito Federal, 22 años, trabajadora de fábrica) 
Completando esta idea, nuestros datos apuntan a que los años de residencia son de escasa relevancia para entender una cierta implicación con el municipio, variable que presenta una correlación significativa $(<0,001)$ muy baja con los años de residencia $(0,094)$. Los años de residencia parecen incidir poco en la intensidad de la identificación con el municipio, lo cual debe entenderse con una baja implicación afectiva de las personas ya nacidas en el territorio, que son las que cuentan con más años de residencia en Valle de Chalco-Solidaridad.

\section{Sentido de lugar y migración internacional}

Anteriormente se ha visto cómo el municipio de Valle de Chalco-Solidaridad ha sido consecuencia de la expansión de la Zona Metropolitana de la Ciudad de México y la falta de suelo disponible para vivienda de las clases más pobres de la ciudad. También se ha observado las dificultades para construir vínculos funcionales y afectivos en un municipio aquejado de diversos problemas sociales y de falta de oportunidades laborales. En este apartado, observaremos qué relación pueden tener estas características del municipio, particularmente la falta de una identidad territorial, que pudieran ser extensibles a otros municipios de áreas metropolitanas de México, con la incidencia en la migración internacional.

Con relación a esta idea, se ha apuntado, en una ocasión anterior, que la razón por la que los destinos de los migrantes de Valle de Chalco-Solidaridad en Estados Unidos son tan dispersos, y los migrantes del municipio no siguen rutas fijas o establecidas, es la fragmentación de las redes sociales en Valle de Chalco-Solidaridad; redes que se articulan a nivel familiar, y no de comunidad. Dicho con otras palabras, cada familia construye su propia red migratoria, que a veces involucra los lugares de origen de las familias en el México rural y no circula información sobre posibles destinos o trabajos en los Estados Unidos que pudiera eventualmente crear rutas más o menos establecidas de migración (Mendoza, 2009).

La familia, por tanto, es el pilar básico de articulación de las redes sociales en el municipio. La familia, en muchos casos, hunde sus raíces en comunidades rurales o en ciudades medias del interior de la República. Sin embargo, al ser preguntados por sus comunidades de origen (excluyendo a los nacidos en Valle de Chalco-Solidaridad), observamos que los encuestados tampoco expresan opiniones muy favorables. El 42,6\% opina que no «le interesa su lugar de origen» (tabla 4); porcentaje similar al que arroja los que desean abandonar Valle de Chalco. Teniendo en cuenta que, en general, es difícil expresar opiniones negativas del lugar de nacimiento o de residencia, los resultados de la encuesta apuntan, de forma clara, a un desarraigo evidente de los moradores de Valle de Chalco, que no se encuentran a gusto en su lugar de residencia, aunque comparten algunos vínculos afectivos con el mismo, en particular con su hogar, ni tampoco valoran positivamente sus lugares de origen, asociados, en muchos casos, a pobreza y abandono. La sensación general que se desprende de los datos de la encuesta, por tanto, es de desapego afectivo en torno a los lugares que conforman la trayectoria migratoria de las personas. 
También, en cierta manera, sorprende el bajo interés relativo que despiertan los Estados Unidos. Los que declaran no estar interesados en ese país alcanzan casi el 40\%, mientras que aquellos que desearían vivir en los EUA apenas superan el 10\% (tabla 4). Este porcentaje tan bajo, en todo caso, indica que la migración internacional no está motivada por una idealización del país vecino, sino, más bien, por la urgencia o la necesidad de abandonar México por razones básicamente económicas.

Esta impresión se confirma, e incluso es más evidente, en el análisis de los adjetivos o de las palabras usados para describir Valle de Chalco, su comunidad de origen y los Estados Unidos (tabla 5). Las respuestas, como cabía esperar, fueron muy diversas (y muy dispersas, con desviaciones estándar relativamente altas, mayor en el caso de los Estados Unidos, menor en el de la comunidad de origen, lo que apunta a una polarización de las respuestas en torno a los extremos), se agruparon y se ordenaron de acuerdo con su intensidad. Además de su polarización, resalta la coherencia en las respuestas de los encuestados, al ser la media consistente en los tres adjetivos (o palabras o frases) dados para definir los diferentes lugares. Si consideramos que los encuestados que ofrecen tres adjetivos, en vez de dos o uno, son los que cuentan con ideas más claras, es interesante constatar que éstos tienen opiniones más negativas. En el caso de Valle de Chalco-Solidaridad, la moda pasa de 4 (positivo; primer adjetivo) a 1 (muy negativo; tercer adjetivo), y la media es de 2,8 a 2,5. Parece que aquellos con opiniones más firmes son los que se decantan por opciones negativas. De los tres lugares, los encuestados tienen opiniones más moderadamente positivas respecto al lugar de origen. Los valores oscilan entre el 3,3 (primer adjetivo) y el 3,0 (tercer adjetivo). Para Estados Unidos, la media muestra una sensación de

Tabla 4. Identificación de los encuestados con el lugar de origen y los Estados Unidos

\begin{tabular}{lcc}
\hline & $N$ & $\%$ \\
\hline Lugar de origen $^{*}$ & & \\
$\quad$ Si pudiera, me regresaría a mi lugar de origen & 168 & 24,7 \\
$\quad$ Extraño mi lugar de origen & 223 & 32,7 \\
$\quad$ No me interesa mi lugar de origen & 290 & 42,6 \\
\hline $\boldsymbol{N} \quad$ & 681 & 100,0 \\
\hline & $\boldsymbol{N}$ & $\%$ \\
\hline Estados Unidos & & \\
$\quad$ Si pudiera, viviría en los Estados Unidos & 79 & 10,7 \\
$\quad$ Me gustaría conocer, pero no viviría & 370 & 49,9 \\
$\quad$ No me interesan los Estados Unidos & 292 & 39,4 \\
\hline $\boldsymbol{N} \quad$ & 741 & 100,0 \\
\hline
\end{tabular}

* Excluidos los nacidos en Valle de Chalco-Solidaridad.

Fuente: encuesta Migración, lugar y empleo en Valle de Chalco-Solidaridad, abril-mayo de 2007. 
indiferencia en los tres adjetivos señalados (2,9), y Valle de Chalco-Solidaridad registra los valores más negativos de los tres.

En esta línea de análisis, en la tabla 6, observamos las valoraciones de los lugares, en función de dos indicadores clave para nuestra investigación: la experiencia migratoria en los Estados Unidos y el lugar de nacimiento. Aquí se comparan las medias en torno a la implicación sobre los lugares, dependiendo

Tabla 5. Valoraciones de los encuestados sobre Valle de Chalco-Solidaridad, el lugar de nacimiento y los Estados Unidos

\begin{tabular}{lccccc}
\hline & Media & Mediana & Moda & Desviación & $\boldsymbol{N}$ \\
\hline Valle de Chalco-Solidaridad & & & & & \\
$\quad$ Adjetivo 1 & 2,8 & 3 & 4 & 1,3 & 753 \\
Adjetivo 2 & 2,5 & 2 & 4 & 1,3 & 553 \\
Adjetivo 3 & 2,5 & 2 & 1 & 1,4 & 367 \\
\hline Comunidad de origen* & & & & & \\
Adjetivo 1 & 3,3 & 4 & 4 & 1,2 & 641 \\
Adjetivo 2 & 3,1 & 4 & 4 & 1,2 & 477 \\
Adjetivo 3 & 3,0 & 3 & 4 & 1,2 & 327 \\
EUA & & & & & \\
Adjetivo 1 & 2,9 & 3 & 1 & 1,6 & 586 \\
Adjetivo 2 & 2,9 & 3 & 1 & 1,6 & 415 \\
Adjetivo 3 & 2,9 & 3 & 1 & 1,7 & 272 \\
\hline
\end{tabular}

* Esta pregunta no se aplica a los nacidos en Valle de Chalco-Solidaridad.

Valores de 1 a 5 . Muy negativo $=1 ;$ muy positivo $=5 ;$ neutro $=3$.

Fuente: encuesta Migración, lugar y empleo en Valle de Chalco-Solidaridad, abril-mayo de 2007.

Tabla 6. Sentido de lugar según experiencia migratoria y lugar de nacimiento del encuestado

\begin{tabular}{|c|c|c|c|c|c|c|c|}
\hline & \multirow[b]{2}{*}{$N$} & \multicolumn{2}{|c|}{$\begin{array}{l}\text { Valle de Chalco- } \\
\text { Solidaridad }\end{array}$} & \multicolumn{2}{|c|}{$\begin{array}{l}\text { Comunidad } \\
\text { de origen }\end{array}$} & \multicolumn{2}{|c|}{ Estados Unidos } \\
\hline & & Media & $D E$ & Media & $D E$ & Media & $D E$ \\
\hline Con experiencia migratoria ${ }^{1}$ & 96 & $1,67^{\star \star}$ & 0,81 & 1,85 & 0,81 & $1,94^{\star *}$ & 0,80 \\
\hline Sin experiencia migratoria & 713 & $1,85^{\star \star}$ & 0,81 & 1,82 & 0,80 & $1,68^{\star *}$ & 0,62 \\
\hline $\begin{array}{l}\text { Nacidos en el Estado } \\
\text { de México }\end{array}$ & 150 & 1,79 & 0,81 & $1,69^{*}$ & 0,76 & $1,89^{\star \star \star}$ & 0,65 \\
\hline $\begin{array}{l}\text { No nacidos en el Estado } \\
\text { de México }\end{array}$ & 659 & 1,83 & 0,81 & $1,84^{*}$ & 0,81 & $1,67^{\star \star \star}$ & 0,64 \\
\hline
\end{tabular}

1. Persona encuestada con experiencia migratoria directa o con miembros del hogar con experiencia directa regresados.

2. Incluye Valle de Chalco-Solidaridad.

3. Excluidos nacidos en Valle de Chalco-Solidaridad.

Las diferencias de las medias son significativas de acuerdo con la prueba $T$ para dos muestras

${ }^{*}<0,1 ;{ }^{* *}<0,05 ;{ }^{* * *}<0,01$.

Fuente: encuesta Migración, lugar y empleo en Valle de Chalco-Solidaridad, abril-mayo de 2007. 
de si la persona cuenta directa o indirectamente, a través de miembros del hogar que han regresado a México, con experiencia migratoria en los Estados Unidos. Resulta destacable que las diferencias entre las medias son significativas con respecto a la identificación con Valle de Chalco-Solidaridad y con los Estados Unidos $(<0,05)$, dependiendo de si se tiene experiencia migratoria.

Con respecto al lugar de nacimiento, sea éste el Estado de México (que incluye Valle de Chalco-Solidaridad) o el resto de la República mexicana, sorprende que las diferencias entre las medias sobre la identificación con Valle de Chalco-Solidaridad no diverjan significativamente. El hecho de haber nacido en este municipio o en otro del Estado de México (particularmente, Ixtapaluca, Los Reyes, Nezahualcóyotl) no tiene ninguna relevancia para entender las opiniones sobre Valle de Chalco-Solidaridad, lo cual indica un fuerte desarraigo, ya que, en principio, una razón básica para sentirse implicado en un lugar es el haber nacido en el mismo. Son, sin embargo, significativas, las divergencias en las medias, dependiendo del lugar de nacimiento, con respecto a Estados Unidos $(<0,01)$ y a la comunidad de origen, aunque en este caso último con un nivel de significación sensiblemente menor $(<0,10)$. El hecho de nacer en el Estado de México incide positivamente en la valoración sobre los Estados Unidos, y negativamente sobre la comunidad de origen, aunque este último dato debería matizarse, porque la pregunta relativa a la comunidad de origen no se aplica a los nacidos en Valle de Chalco.

Son más claras y reveladoras las diferencias en las medias, que dependen de la experiencia migratoria de la persona encuestada. Es destacable, en este sentido, que las personas con experiencia migratoria opten por enunciados más negativos sobre Valle de Chalco-Solidaridad, que aquellos que no han emigrado a los Estados Unidos (la diferencia de las medias es 0,22). De igual manera, con la misma intensidad, pero en sentido contrario, se observa que los migrantes o las personas con experiencia migratoria indirecta cuentan con opiniones más positivas sobre los Estados Unidos que los que no cuentan con dicha experiencia. Dicho con otras palabras, la experiencia migratoria incide negativamente en la implicación personal en Valle de Chalco-Solidaridad y positivamente en la de los Estados Unidos.

\section{Conclusiones}

Valle de Chalco-Solidaridad es un municipio de reciente creación de la zona metropolitana de la Ciudad de México. Es reciente en un doble sentido. Se creó oficialmente en 1994 y creció con la llegada de numerosos migrantes procedentes tanto del interior de la misma zona metropolitana, como de áreas rurales mexicanas, de tal forma que sus tasas de crecimiento demográfico se situaron entre las más altas en los años noventa. La ocupación del espacio por parte de estos migrantes internos no siguió siempre los cauces legales de ocupación del suelo urbano.

En cuanto a los patrones de migración internacional, los datos denotan una gran incidencia de la migración en los hogares de Valle de Chalco-Solidaridad, 
señalan que el primer viaje se realizó mayoritariamente en el periodo 20002007 y, más importante, muestran una elevada tasa de retorno. Estas cifras parecen apuntar un alto impacto de las crisis económicas de principios del siglo Xxi en la periferia urbana de la Ciudad de México, así como una alta precariedad laboral que también sufren los migrantes en los Estados Unidos, indicada por los índices de retorno elevados.

La encuesta y las entrevistas también sugieren que se da un proceso de consolidación de una clase proletaria transnacional que, en cierta manera, acepta la precariedad y la inestabilidad laboral, y reconoce en la migración internacional una estrategia para la mejora del bienestar de los hogares. En definitiva, se aprecia una transnacionalización de la pobreza: los migrantes de Valle de Chalco-Solidaridad son pobres que ven en la migración una «forma de vivir bien», que, en la mayoría de casos, se reduce a la construcción de una casa propia o poseer un automóvil. Sin embargo, esta mejora es sólo temporal y, en todo caso, no permite "escapar» del círculo de la pobreza a sus descendientes, que también se ven obligados, en muchos casos, a emigrar.

Valle de Chalco-Solidaridad, además, es un lugar que no satisface las necesidades de empleo u ocio de la población; de tal forma que se da, como sugiere Lindón (2000), una forma de habitar caracterizada por el rechazo atópico, sin vinculación afectiva con respecto al lugar de residencia. En estas situaciones, no es de sorprender que los sujetos estén dispuestos a relocalizarse o a migrar en la medida que visualicen condiciones que ofrezcan alguna ventaja respecto a la actual. En Valle de Chalco-Solidaridad, se da un tipo de sujeto social con una trayectoria de vida marcada por una alta movilidad territorial y que, a pesar de su anclaje actual, siente un apego débil al lugar. Habría que añadir que ese apego no se observa sólo con respecto a su lugar de residencia actual, sino que es extensible al lugar de origen y a los Estados Unidos. En este sentido, todo apunta a que la pobreza es un elemento que detiene la participación social y la construcción de un sentido de pertenencia.

En particular, para Valle de Chalco-Solidaridad, es notorio que la mayor fuente de apego radica en el hecho de que este municipio de la periferia oriental de la Ciudad de México representa el acceso a la propiedad de muchos de sus residentes. Se trata de un vínculo débil, ya que la mayoría de sus habitantes no se sienten arraigados a su municipio por los años de residencia o las relaciones sociales que ahí han desarrollado; se trata de un apego al lugar por posesión, no por arraigo. Las relaciones sociales, por otro lado, giran en torno a las familias, y no se establecen a nivel de comunidad.

Finalmente, es importante señalar que, en tanto que los lugares no provean las condiciones y los servicios que la población demande y estime como los adecuados para la consecución de sus metas, aspectos a los que remite la dimensión de vinculación funcional, no importa como de arraigado se esté a un lugar en términos afectivos o de identidad, la migración siempre será una opción en situaciones de crisis, en un contexto de alta precariedad laboral y penuria económica familiar como la que viven una buena parte de los hogares vallechalquenses. En ese aspecto, la encuesta y las entrevistas sugieren que el 
sentido de lugar hacia la localidad es profundamente «instrumental», es decir, el lugar (el municipio de Valle de Chalco-Solidaridad) es significativo o relevante con relación a lo que provee y lo que no provee en términos de bienes, servicios y oportunidades formales de trabajo (véase también Butz y Eyles, 1997).

A manera de cierre, es oportuno reflexionar que, en el actual contexto de la globalización (que comporta un aumento en la movilidad espacial de las personas), los estudios sobre transnacionalismo y las frecuentes referencias a lo espacial y al territorio son parte de la tendencia actual de redescubrimiento de la espacialidad de la vida social. La geografía, como una de las ciencias que más ha teorizado sobre el espacio, puede contribuir a explorar la relevancia de los lugares en los procesos migratorios; un tema, por otro lado, «en construcción» en los estudios de migración que, pensamos, ha recibido un impulso a partir de la discusión de nuevos paradigmas, como el de las «nuevas movilidades» (Creswell, 2006; Sheller y Urry, 2006; Blunt, 2007).

\section{Referencias bibliográficas}

Agnew, John A. (1987). Place and politics: The geographical mediation of state and society. Boston: Allen and Unwin.

Agnew, John A. y Duncan, James S. (eds.) (1989). The power of place: Bringing together geographical and sociological imaginations. Boston: Unwin Hyman.

Aguilar, Miguel Ángel (2000). "Uso del espacio e identidad del lugar en Valle de Chalco». En: Hiernaux, Daniel; Lindón, Alicia y Noyola, Jaime (coords.). La construcción social de un territorio emergente: El Valle de Chalco. Zinacantepec, Estado de México: El Colegio Mexiquense y Ayuntamiento de Valle de ChalcoSolidaridad, 275-287.

Altman, Irwin y Low, Setha M. (eds.) (1992). Place attachment. Human behavior and environment, 12. Nueva York: Plenum.

Anderson, Kay y Gale, Fay (1992). Inventing places: Studies in cultural geography. Sydney: Longman Cheshire.

Arefi, Mahyar (1999). «Non-Place and Placelessness as Narratives of Loss: Rethinking the Notion of Place». Journal of Urban Design, 4 (2), 179-193.

Azuela, Antonio (1989). La ciudad, la propiedad privada y el derecho. Ciudad de México: El Colegio de México.

Basso, Keith H. (1996). Wisdom sits in places: Landscape and language among the Western Apache. Albuquerque: University of New Mexico Press.

BLunT, Alison (2007). «Cultural geographies of migration: Mobility, transnationality and diaspora". Progress in Human Geography, 31 (5), 684-694.

Buttimer, Anne (1976). «Exploring the dynamics of lifeworld». Annals of the Association of American Geographers, 66 (2), 277-292.

Buttimer, Anne y Seamon, David (eds.) (1980). The human experience of space and place. Nueva York: St. Martin's Press.

Butz, David y EyLEs, John (1997). «Reconceptualizing senses of place: Social relations, ideology and ecology». Geografiska Annaler, 79 B (1), 1-25.

Cамpвell, David (1996). «Political prosaics, transversal politics, and the anarchical world». En: Shapiro, Michael y HaYward Alker (eds.). Challenging boundaries. Minneapolis: University of Minnesota Press, 7-31. 
Canales, Alejandro (2002). "Migración y trabajo en la era de la globalización: El caso de la migración México-Estados Unidos en la década de 1990». Papeles de Población, 33 (3), 47-78.

Conradson, David y Latham, Allan (2005). «Transnational urbanism: Attending to everyday practices and mobilities». Journal of Ethnic and Migration Studies, 31(2), 227-233.

Consejo Nacional de Población (CONAPO) (2002). Índice de intensidad migratoria México Estados Unidos 2000. Ciudad de México: CONAPO. [http://www. conapo.gob.mx/publicaciones/migra4.htm; consulta: 24 de julio de 2010]

Crang, Mike (1998). Cultural geography. Londres: Routledge.

Crang, Mike y Thrift, Nigel (eds.) (2000). Thinking space. Londres: Routledge.

Cresswell, Tim (2004). Place: A short introduction. Oxford: Blackwell.

- (2006). On the move: Mobility in the modern Western World. Londres: Routledge.

Ehrkamp, Patricia (2005). "Placing identities: Transnational practices and local attachments of Turkish immigrants in Germany». Journal of Ethnic and Migration Studies, 31 (2), 345-364.

Eisenhauer, Brian W.; Krannich, Richard S. y Blahna, Dale S. (2000). «Attachments to special places on public lands: An analysis of activities, reasons for attachments, and community connections». Society \& Natural Resource: An International Journal, 13 (5), 421-441.

Escobar, Agustín; Hailbronner, Kay; Martin, Philip y Meza, Liliana (2006). "Migration and development: Mexico and Turkey». International Migration Review, 40 (3), 707-718.

Eyles, John (1985). Senses of place. Warrington: Silverbrook Press.

FINDLAY, Allan y LI, F.L.N. (1997). «An auto-biographical approach to understanding migration: The case of Hong Kong emigrants». Area, 29 (1), 34-44.

Galeana Rodríguez, Fernando (2005). «Demanda del dominio pleno en el ejido: Derechos de propiedad y crédito rural». Estudios Agrarios, 19, 19-28.

Gallagher, Winifred (1993). The power of place: How our surroundings shape our thoughts, emotions, and actions. Nueva York: Harper-Perennial.

Gutting, Daniel (1996). "Narrative identity and residential history». Area, 28 (4), 482-490.

Haeberle, Steven H. (1988). «People or place: variations in community leaders' subjective definitions of neighborhood». Urban Affairs Quarterly, 23 (4), 616-634.

Halfacree, Keith y Boyle, Paul (1993). "The challenge facing migration research: The case for a biographical approach». Progress in Human Geography, 17, 333-358.

Halpenny, Elizabeth A. (2010) «Pro-environmental behaviours and park visitors: The effect of place attachment». Journal of Environmental Psychology, 30, 409-421.

Hernández, Bernardo; Hidalgo, Carmen; Salazar-Laplace, Esther y Hess, Stephany (2007). «Place attachment and place identity in natives and non-natives». Journal of Environmental Psychology, 27 (4), 310-319.

Hidalgo, Carmen y Hernández, Bernardo (2001). «Place attachment: conceptual and empirical questions». Journal of Environmental Psychology, 21 (3), 273-281.

Hiernaux, Daniel (1995). Nueva periferia, vieja metrópoli: El Valle de Chalco, Ciudad de México. Ciudad de México: Universidad Autónoma Metropolitana-Xochimilco.

- (1999). «Los frutos amargos de la globalización: Expansión y reestructuración metropolitana de la ciudad de México". EURE. Revista Latinoamericana de Estudios Urbano Regionales, 25 (76), 1-34. [http://redalyc.uamex.mx; consulta: 15 de noviembre de 2010] 
Hiernaux, Daniel y Lindón Alicia (1997). «Producción del espacio y regularización de la tenencia de la tierra». En: Azuela, Antonio y François, Tomas (comps.). El acceso de los pobres al suelo urbano. Ciudad de México: CEMCA, Instituto de Investigaciones Sociales de la UNAM y Paradigma, 249-276.

Hiss, Tony (1990). The experience of place. Nueva York: Alfred A. Knopf.

Instituto Nacional de Estadística y Geografía (INEGI) (2007). Cartografía Geoestadistica Urbana: Municipio de Valle de Chalco-Solidaridad. Ciudad de México: INEGI.

- (2010a). Conteo de Población y Vivienda 1995. Ciudad de México: INEGI. [www.inegi.gob.mx; consulta: 24 de julio de 2010]

- (2010b). Censo de Población y Vivienda 2000. Ciudad de México: INEGI. [www.inegi.gob.mx; consulta: 24 de julio de 2010]

- (2010c). Conteo de Población y Vivienda 2005. Ciudad de México: INEGI. [www.inegi.gob.mx; consulta: 24 de julio de 2010]

Iracheta, Alfonso (2003). "Gobernabilidad en la Zona Metropolitana del Valle de México». Papeles de Población, 36 (2), 211-239.

Johnston, Ron J. (1991). A question of place: Exploring the practice of human geography. Oxford: Basil Blackwell.

Jorgensen, Bradley S. y Stedman, Richard C. (2001). «Sense of place as an attitude: Lakeshore property owners' attitudes toward their properties». Journal of Environmental Psychology, 21 (3), 233-248.

- (2006). «A comparative analysis of predictors of sense of place dimensions: Attachment to, dependence on, and identification with lakeshore properties». Journal of Environmental Management, 79, 316-327.

LALLI, Marco (1992). "Urban-related identity: Theory, measurement, and empirical findings». Journal of Environmental Psychology, 12 (4), 285-303.

Light, Andrew y Smith, Jonathan (eds.) (1998). Philosophies of place. Lanham: Rowman \& Littlefield.

Lindón, Alicia (1999). De la trama de la cotidianidad a los modos de vida urbanos: El Valle de Chalco. Ciudad de México: El Colegio de México y El Colegio Mexiquense.

- (2000). «La espacialidad del trabajo, la socialidad familiar y el ideario del progreso: Hacia nuevos modos de vida urbanos en el Valle de Chalco». En: Hiernaux, Daniel; Lindón, Alicia y Noyola, Jaime (coords.). La construcción social de un territorio emergente: El Valle de Chalco. Zinacantepec, Estado de México: El Colegio Mexiquense y Ayuntamiento de Valle de Chalco-Solidaridad, 289-312.

- (2005a). «El mito de la casa propia y las formas de habitar». Scripta Nova. Revista Electrónica de Geografía y Ciencias Sociales, 194 (20). [http://www.ub.es/geocrit/ sn/sn-194-20.htm; consulta: 8 de junio de 2010]

- (2005b). «Figuras de la territorialidad en la periferia metropolitana: topofilias y topofobias». En: Reguillo, Rossana y Godoy, Marcial Anativia (eds.). Ciudades translocales: Espacios, flujos, representación. Perspectivas desde las Américas. Ciudad de México: Instituto Tecnológico y de Estudios Superiores de Occidente y Social Science Research, 145-172.

López, Liliana (2005). «Las calles de la Ciudad de México: Espacio público y paisaje urbano». En: Castillo, Alejandro (comp.). Recomposiciones regionales, sociales, políticas y culturales en el mundo actual. Ciudad de México: Universidad Autónoma Metropolitana-Xochimilco, 453-470. 
Massey, Doreen (1994). «A global sense of place». En: Massey, Doreen (ed.). Space, place and gender. Cambridge: Polity Press, 146-156.

- (1995). "The conceptualization of place». En: MAssey, Doreen y Jess, Patt (eds.). A place in the world?: Places, Cultures and Globalization. Oxford: Oxford University Press, 45-85.

Mendoza, Cristóbal (2006a). «Geografía de la población». En: Hiernaux, Daniel y Lindón, Alicia (coords.). Tratado de Geografía Humana. Barcelona: Anthropos y Universidad Autónoma Metropolitana-Iztapalapa, 147-169.

- (2006b). «Transnational spaces through local places: Mexican immigrants in Albuquerque (New Mexico)». Journal of Anthropological Research, 62 (4), 539-562.

- (2009). «La emergencia de la migración internacional en la periferia empobrecida de la ciudad de México: Valle de Chalco-Solidaridad, Estado de México». Migraciones Internacionales, 5 (2), 5-37.

Mitchell, Katharyne (2004). Crossing the neoliberal line: Pacific rim migration and the metropolis. Filadelfia: Temple University Press.

Olivera, Guillermo (2004). "Trayectoria de las reservas territoriales en México: Irregularidad, desarrollo urbano y administración municipal tras la reforma constitucional de 1992». EURE. Revista Latinoamericana de Estudios Urbano Regionales, 27 (81), 61-84. [http://redalyc.uamex.mx; consulta: 15 de noviembre de 2010]

Ortiz Guitart, Anna (2004). "Reflexiones en torno a la construcción cotidiana y colectiva del sentido de lugar en Barcelona». Polis: Investigación y Análisis Sociopolítico y Psicosocial, 4 (1), 161-183.

PArnreiter, Christof (2002) "Ciudad de México: El camino hacia una ciudad global». EURE. Revista Latinoamericana de Estudios Urbano Regionales, 28 (85). [http:// redalyc.uamex.mx; consulta: 15 de noviembre de 2010]

Pascual de Sans, Àngels (2004). "Sense of place and migration histories: Idiotopy and idiotope». Area, 36 (4), 348-357.

PeEt, Richard (ed.) (1998). Modern geographical thought. Oxford: Wiley-Blackwell.

Pellegrini, Pasquale A. y Fotheringham, A. Stewart (2002). «Modelling spatial choice: A review and synthesis in a migration context». Progress in Human Geography, 26 (4), 487-510.

Pred, Allan (1984). «Place as historically contingent process: structuration and the time-geography of becoming places». Annals of the Association of American Geographers, 74 (2), 279-297.

Proshansky, Harold; Fabian, Abbe y Kaminoff, Robert (1983). «Place-identity: Physical world socialization of the self». Journal of Environmental Psychology, 3 (1), 57-83.

Relph, Edward (1976). Place and placelessness. Londres: Pion.

Raymond, Christopher M.; Brown, Gregory y Weber, Delene (2010). «The measurement of place attachment: Personal, community and environmental connections». Journal of Environmental Psychology, 30, 422-434.

Rodman, Margaret C. (1992). "Empowering place: Multilocality and multivocality». American Anthropologist, 94 (3), 640-656.

Rose, Gillian (1995). «Geography and gender, cartographies and corporealities». Progress in Human Geography, 19 (4), 544-548.

SACK, David (1993). "The power of place and space». The Geographical Review, 83 (3), 326-329.

Seamon, David y Mugerauer, Robert (eds.) (1985). Dwelling, place and environment: Towards a phenomenology of person and world. Nueva York: Columbia University Press. 
Seamon, David (ed.) (1993). Dwelling, seeing and designing: Toward a phenomenological ecology. Albany: State University of New York Press.

Shamai, Shmuel (1991). "Sense of place: An empirical measurement». Geoforum, 22 (3), 347-358.

Shamai, Shmuel e Ilatov, Zinaida (2005). «Measuring sense of place: Methodological aspects». Tijdschrift voor Economische en Sociale Geografie, 96 (5), 467-476.

Sheller, Mimi y Urry, John (2006). "The new mobilities paradigm». Environment and Planning A, 38 (2), 207-226.

Silvey, Rachel y Lawson, Victoria (1999). "Placing the Migrant». Annals of the Association of American Geographers, 89 (1), 121-132.

Thrift, Nigel (2004). «Movement-space: the changing domain of thinking thinking resulting from the development of new kinds of spatial awareness». Economy and Society, 33 (4), 582-604.

Tuan, Yi-Fu (1974). Topophilia: A study of environmental perception, attitudes, and values. Englewood Cliffs: Prentice-Hall.

- (1977). Space and place. Minneapolis: University of Minnesota Press.

Twigger-Ross, Clare L. y Uzzell, David L. (1996). «Place and identity processes». Journal of Environmental Psychology, 16, 205-220.

White, Paul y Jackson, Peter (1995). "(Re)theorizing population geography». International Journal of Population Geography, 1, 111-123.

Williams, Daniel R. y Stewart, Susan (1998). «Sense of place: An elusive concept that is finding a home in ecosystem management». Journal of Forestry, 96 (5), $18-25$. 